\title{
Highly Effective Conditions for Nickel-Mediated Heck Cyclization Cascades Starting from Aryl and Vinyl Triflates
}

Jonathan H. Keim, Andrew W. M. Cummins, and Scott A. Snyder $\left.{ }^{*}\right]$

Department of Chemistry, The University of Chicago, 5735 S. Ellis Avenue, Chicago, IL 60637 (USA)

\begin{abstract}
In contrast to the tremendous power of Pd-based Mizoroki-Heck reactions, methods to achieve such processes with other metals, particularly $\mathrm{Ni}$, are generally lacking. Herein, we delineate specific conditions that can enable cascade variants of these $\mathrm{C}-\mathrm{C}$ bond forming events to proceed smoothly under Ni catalysis. Critically, these reactions work with equal facility as their Pd-initiated counterparts when conducted intramolecularly, and in many cases are devoid of any $\mathrm{Ni}-\mathrm{H}$-mediated alkene isomerization within the starting materials and/or products as has typically been observed with previous Ni-based protocols. When conducted intermolecularly, the developed variant affords unique regioselectivity in product formation, substantively favoring 6-endo additions over the more standard 5-exo counterparts observed under Pd-based conditions. Finally, applications of the developed procedures to two different natural product syntheses are described.
\end{abstract}

Among methods for cascade-based bond constructions, the Mizoroki-Heck reaction is particularly notable for its ability to quickly and stereoselectively generate complex polycyclic systems from far simpler precursors.[1] Indeed, such cascades have long proven valuable for the effective synthesis of natural products, with operations within total syntheses of $\mathbf{3},{ }^{[2]} \mathbf{5 ,},[3]$ and $\mathbf{6}^{[4]}$ (such as the conversion of $\mathbf{1} \rightarrow \mathbf{2}$, Scheme 1 ) being representative cases following the seminal example utilized in Overman's route to (-)scopadulpic acid A (4). ${ }^{[5]}$ However, despite the wealth of literature around this Pdmediated reaction, the corresponding Ni variant remains largely unstudied despite the recent resurgence in interest around nickel catalysis. ${ }^{[6-9]}$ In fact, when we began this project in 2018, we could only identify one intermolecular case involving alkenes.[10] In addition, we were unaware of any examples of an intramolecular Ni-mediated Heck cascade involving multiple $\mathrm{C}-\mathrm{C}$ bond construction via consecutive migratory insertions and terminated through $\beta$ - $\mathrm{H}$ elimination and reductive elimination of the resultant $\mathrm{Ni}-\mathrm{H}$ species. One leading feature responsible for this deficiency is the much higher potential for alkene isomerization in both starting materials and products due to long-lived $\mathrm{Ni}-\mathrm{H}$ intermediates, an issue that is rarely observed in the corresponding Pd-based cascades. Herein we delineate effective condition sets that can achieve this process for a wide variety of aryl and vinyl triflate substrates both intra- and intermolecularly. Critically, while it proceeds in yields commensurate to their Pd-based counterparts, in some cases unique products are formed selectively that are otherwise unobtainable with Pd. Moreover, alkene isomerization induced by long-lived $\mathrm{Ni}-\mathrm{H}$ species is also avoided. Finally, the successful application of the developed solutions to the total synthesis of two natural products is described. 


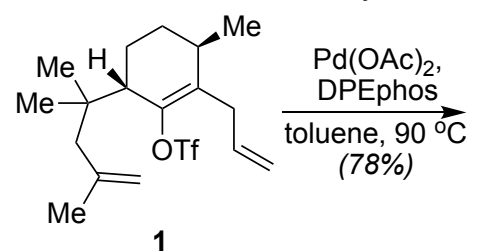

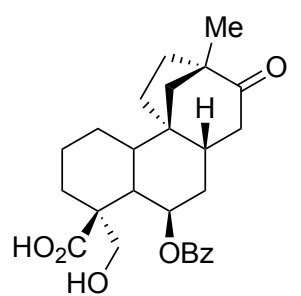

4: scopadulpic acid $A$ [Overman, 1993]<smiles>Cc1cc2c(cc1C(=O)c1occ3c1C(C)CCC3)C(=O)C=CC2=O</smiles>

5: (+)-xestoquinone [Keay, 1996]

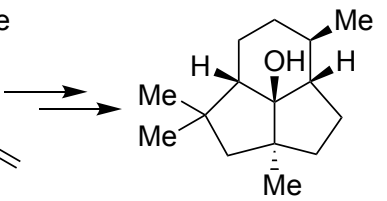

3: (-)-presilphiperfolan-8-ol [Snyder, 2017]<smiles>O=C1c2cc(O)cc(O)c2[C@H](c2ccc(O)cc2)[C@H]1c1ccc(O)cc1</smiles>

6: pauciflorol $\mathrm{F}$ [Sarpong, 2011]

Representative Examples of Recent Ni-Mediated Heck Reactions

[Garg/Senanayake, 2016]<smiles>C/C=C(/C)C(=O)N(C)c1ccccc1Br</smiles>

7

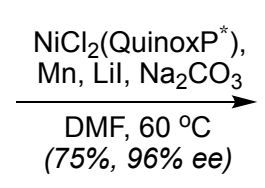

$\mathrm{DMF}, 60^{\circ} \mathrm{C}$
$(75 \%, 96 \%$ ee)

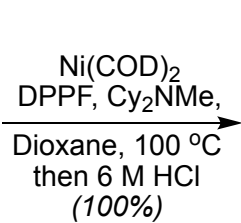

(100\%)

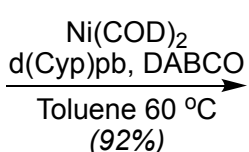<smiles>C=C[C@]1(C)C(=O)N(C)c2ccccc21</smiles>

8<smiles>C/C=C/c1ccc(C(C)=O)c(OC)c1</smiles>

11

14

This work: Powerful Conditions for Intra- and Intermolecular Ni-Heck Cascades

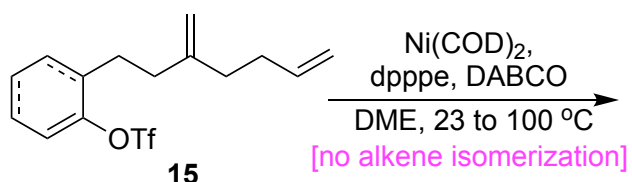<smiles>C=C1CCC2(CCc3ccccc32)C1</smiles>

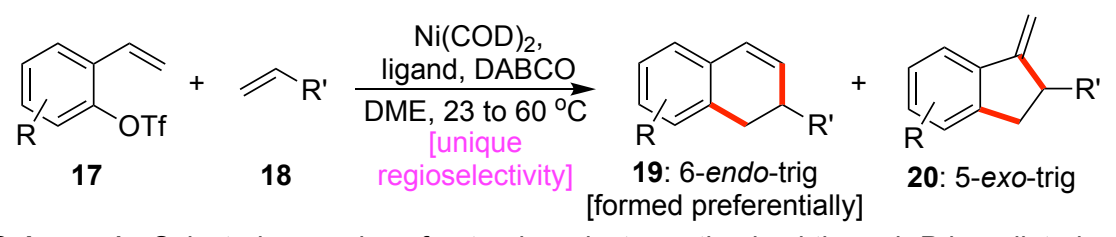

Scheme 1. Selected examples of natural products synthesized through Pd-mediated Heck cascades, prior efforts to effect similar reactions using $\mathrm{Ni}$, and the key elements of this work: effective conditions to promote both intra- and intermolecular $\mathrm{Ni}$ mediated Heck cascades with both high alkene positional control and, in selected cases, with unique regioselectivity versus $\mathrm{Pd}$-mediated cases.

Although the power of Ni-mediated bond constructions has grown significantly in recent years, its gap in synthetic potential versus that of Pd as it specifically relates to Heck 
chemistry is reflective of its distinct reactivity within the context of the reaction's mechanism. ${ }^{[11]}$ For example, while Ni's enhanced ability to undergo oxidative addition can enable the use of traditionally sluggish and/or unreactive coupling partners, such as chlorides, ${ }^{[9 g]}$ ethers, ${ }^{[9 c]}$ pivalates, ${ }^{[9 b]}$ amides, ${ }^{[9 e]}$ or even alkyl substrates, $\left.{ }^{[9]}\right]$ the cost for this proclivity is that reductive elimination of the resultant $\mathrm{Ni}-\mathrm{H}$ is far more challenging. Indeed, while $\mathrm{Pd}-\mathrm{H}$ species undergo facile and rapid base-mediated reductive elimination with amine and carbonate bases, the corresponding $\mathrm{Ni}-\mathrm{H}$ species can require strong organometallic bases ${ }^{[9 c]}$ and/or high temperatures to affect the sluggish deprotonation. ${ }^{[14]}$ As a result, traditional base-mediated Heck conditions tend to afford relatively long-lived $\mathrm{Ni}-\mathrm{H}$ species that can isomerize olefins in both the starting material and product(s), $, 7,9 e, 12,13]$ thereby causing selectivity issues typically unobserved in Pd-based Heck cyclization variants.

To date, two main approaches have arisen to mitigate these off-cycle pathways and promote recalcitrant reductive elimination of $\mathrm{Ni}-\mathrm{H}$, thereby enabling some $\mathrm{Ni}-\mathrm{Heck}$ variants to proceed effectively. The first avoids base-mediated reductive elimination altogether through the use of a stoichiometric reductant such as $\mathrm{Mn}^{[6]}$ or $\mathrm{Zn} .{ }^{[9 \mathrm{~d}]}$ However, while these conditions are effective for aryl and vinyl halides (as in the conversion of $\mathbf{7}$ into 8), the corresponding triflates often perform poorly.[6,15] Alternatively, base-mediated reductive elimination can be promoted by accessing the cationic Heck pathway[1,7,8] through the use of triflate coupling partners or halide-abstracting reagents. In this approach, the resultant cationic $\mathrm{Ni}-\mathrm{H}$ species are considerably more electron poor, and thus sufficiently acidic ${ }^{[16]}$ that amine bases are able to effectively regenerate $\mathrm{Ni}(0)$ via deprotonation; however, these $\mathrm{Ni}-\mathrm{H}$ species can still cause substantial olefin isomerization (as was observed during the formation of 11), ,7] thereby limiting substrate scope and/or requiring the use of bulky ligands (as deployed for the synthesis of 14) to inhibit reinsertion. ${ }^{[8]}$ More recently, and concurrent with the studies reported here, three useful reports on Ni-Heck type cascades have been published, but none afford a general approach which addresses the core issue involving $\mathrm{Ni}-\mathrm{H}$ mediated isomerization. ${ }^{[17]}$ The first of these from the Kong group required gem-difluoroalkene coupling partners and proceeded via $\mathrm{Ni}-$ F species rather than the usual $\mathrm{Ni}-\mathrm{H}$ variants. ${ }^{[17 a]}$ A later approach by the same group utilized an elegant hydrogen borrowing strategy to take advantage of the $\mathrm{Ni}-\mathrm{H}$ species, but proved limited to the formation of indanone substrates.[17b] And finally, a method developed by the Rong group is specific to generating indenones. ${ }^{[17 c]}$ As such, we sought to develop a general approach by which to achieve Ni-based Heck cascades using aryl and vinyl substrates, predominantly in the form of their respective triflates, ${ }^{[18]}$ which would be mild enough to enable the smooth formation of multiple bonds with similar ease to their Pd-based cousins without any alkene isomerization issues.

Our model substrate was dienyl aryl triflate $\mathbf{2 1}$ (Table 1). Following extensive screening and optimization (see the Supporting Information section for full details), we identified a protocol that afforded spirocycle 22 in $74 \%$ yield after $4 \mathrm{~h}$ at $23^{\circ} \mathrm{C}$ using catalytic $\mathrm{Ni}(\mathrm{COD})_{2}$ (entry 1 ). These conditions afforded only trace alkene isomerization products as detected by several spectroscopic techniques. While several factors were critical to this success, the two that were most significant were the use of DABCO as the base and the bidentate phosphine dpppe as the ligand. Indeed, in our screening we found 
that traditional bases for Pd-based Heck reactions such as $\mathrm{K}_{2} \mathrm{CO}_{3}, \mathrm{Et}_{3} \mathrm{~N}$, and $i-\mathrm{Pr}_{2} \mathrm{NEt}$ proved ineffective at suppressing alkene isomerization. We suspect this outcome reflects $\mathrm{Ni}-\mathrm{H}^{\prime} \mathrm{s}$ lower acidity[11a,16] compared to $\mathrm{Pd}-\mathrm{H}$ and/or the increased steric demand arising from shorter Ni-P bonds ${ }^{[11 \mathrm{bc}]}$ within the active complex. With DABCO it is likely that we are effectively achieving a kinetically favorable deprotonation, and thus a shorter lifetime for any intermediate $\mathrm{Ni}-\mathrm{H}$ species. That supposition is reasonable given that DABCO has a $p \mathrm{~K}_{\mathrm{a}}$ similar to $\mathrm{Et}_{3} \mathrm{~N}^{[19]}$ and has previously been shown ${ }^{[8]}$ to inhibit $\mathrm{Ni}-\mathrm{H}$ mediated isomerization in related contexts. The choice of ligand was equally important, with our findings (see SI for greater information) revealing a strong correlation between the bite angle and the overall efficacy of the reaction. Ligands with small bite angles (such as dppm) afforded only modest conversion and poor yield, while optimal results were obtained with dpppe. Intriguingly, although ligands with even larger bite angles have been reported $[7,20]$ in other cases to effectively promote reductive elimination, we found in this application that the angle of dpppe was optimal, as further upward variations of this parameter led to decreased yield.

Table 1. Comparison of our optimized cyclization conditions to other literature conditions for Ni-mediated Heck reactions.

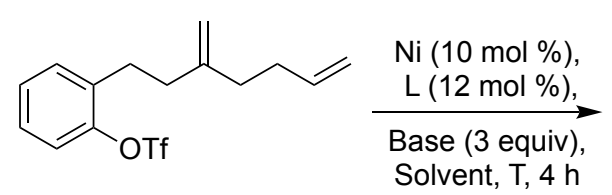

21

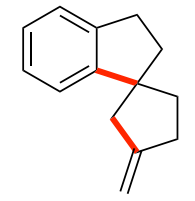

22

\begin{tabular}{ccccccc}
\hline Entry & $\mathrm{Ni}$ Source & Ligand & Solvent & Base & $\mathrm{T}\left({ }^{\circ} \mathrm{C}\right)$ & Yield $(\%)^{[\mathrm{a}]}$ \\
\hline 1 & $\mathrm{Ni}(\mathrm{COD})_{2}$ & dpppe & DME & $\mathrm{DABCO}$ & 23 & 74 \\
$2^{[7]}$ & $\mathrm{Ni}(\mathrm{COD})_{2}$ & $\mathrm{dppf}$ & dioxane & $\mathrm{Cy}_{2} \mathrm{NMe}$ & 100 & 9 \\
$3^{[8]}$ & $\mathrm{Ni}(\mathrm{COD})_{2}$ & $\mathrm{~d}(\mathrm{Cyp}) \mathrm{pbb}$ & toluene & $\mathrm{DABCO}$ & 60 & 11 \\
$4^{[9 \mathrm{~h}]}$ & $\mathrm{Ni}(\mathrm{COD})_{2}$ & Triphos & toluene & $\mathrm{TMP}$ & 110 & 13 \\
$5^{[9 \mathrm{~b}]}$ & $\mathrm{Ni}(\mathrm{COD})_{2}$ & dppf & toluene & $\mathrm{K}_{3} \mathrm{PO}_{4}$ & 125 & 7 \\
$6^{[9 \mathrm{~g}]}$ & $\mathrm{Ni}(\mathrm{COD})_{2}$ & dpephos & toluene & $\mathrm{KO}_{-}-\mathrm{Bu}$ & 80 & 4 \\
$7^{[6][b]]}$ & $\mathrm{NiCl}_{2}(\mathrm{Pn}-\mathrm{Bu})_{3}$ & - & DMF & $\mathrm{Na}_{2} \mathrm{CO}_{3}$ & 60 & 7 \\
8 & $\mathrm{Ni}(\mathrm{COD})_{2}$ & dpephos & toluene & $\mathrm{Cy}_{2} \mathrm{NMe}^{2}$ & 100 & 15 \\
\hline
\end{tabular}

[a] Determined by GC using dodecane as an internal standard; [b] Performed with 3 equiv of $\mathrm{Mn}$ as an added stoichiometric reducing agent.

Comparison of optimized conditions for a monocyclization reaction

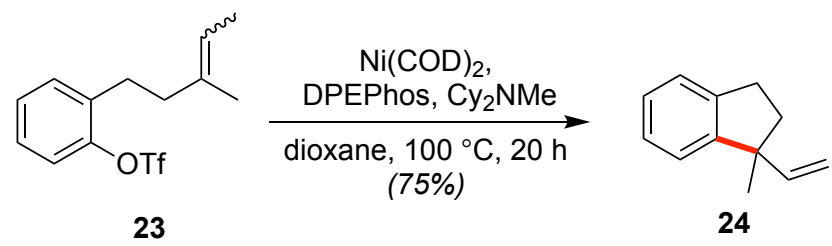

As one reflection of the uniqueness and overall efficacy of these conditions, we attempted the same reaction process with all literature reported protocols for both basemediated ${ }^{[7,8,9 \mathrm{bgh}]}$ and reducing metal[ ${ }^{[6]} \mathrm{Ni}$-Heck conditions (entries 2-7). In all cases, these alternatives afforded poor product yields and/or significant alkene isomerization under 
similar reaction times as our optimal conditions (i.e. 20 h). Further, the significantly higher yield of our conditions to the closely related ones reported by Skrydstrup ${ }^{[7]}$ and Jamison ${ }^{[8]}$ clearly demonstrates how critical the appropriate combination of base and ligand are for the success of this cascade; in that same spirit, it is worth noting that conditions we had optimized separately for the monocyclization of substrate $\mathbf{2 3}$ to generate $\mathbf{2 4}$ (a product where alkene isomerization is not possible), was highly ineffective for the cascade variant starting from 21 (entry 8), thus further illustrating the unique challenges of the cascade events. Pleasingly, our optimal conditions worked equally well with the corresponding nonaflate starting material (76\%), while the chloride, bromide, and tosylate variants of 21 were also competent in leading to 22 , though in slightly reduced yields (42-54\%) and with the requirement of using TESOTf ${ }^{[8]}$ to ensure that the reaction proceeded via a cationic pathway (see SI). Finally, by using the Cornella group's precatalyst, $\mathrm{Ni}\left({ }^{\mathrm{F}} \mathrm{stb}\right)_{3},{ }^{[21]}$ the reaction could be set up using standard Schlenk technique, albeit with a modest decrease in yield $(47 \%)$ relative to the corresponding reaction being performed in the glovebox. Intriguingly, the Engle group's precatalyst, $\mathrm{Ni}(\mathrm{COD})(\mathrm{DQ}),{ }^{[22]}$ showed similar reactivity to $\mathrm{Ni}\left({ }^{\mathrm{F}} \mathrm{stb}\right)_{3}$, but only when utilized inside the glove box as under Schlenk conditions no conversion was observed.

With these conditions in hand, we next explored the reaction scope as shown in Table 2. Here we focused primarily on accessing products previously obtained through $\mathrm{Pd}$ based Heck cascades ${ }^{[23]}$ to establish direct comparisons to this $\mathrm{Ni}$-based protocol and/or determine if any distinct reactivity was possible. While our initial screens were run at $100{ }^{\circ} \mathrm{C}$, we found that most substrates performed as well, or even better, at lower temperatures with many converting smoothly at $23^{\circ} \mathrm{C}$. The reaction also performed well on scale as revealed by a second execution of our model system (Table 2, entry 1), which was conducted using $10 \mathrm{mmol}$ of $\mathbf{2 1}$ with an improvement in yield (87\%) versus that obtained in our optimization studies. Pleasingly, a range of spirocyclic polycycles (i.e. 26, 28, and 30), including the product of a tricyclization, could be obtained in yields that were generally commensurate to those reported for their Pd-based counterparts. ${ }^{[23 a b]}$ In the case of substrates 31 and $\mathbf{3 4}$ (entries 5 and 6), slightly superior product and d.r. ratios were obtained (for which Pd afforded a 1.5:1 ratio for 32:33 and 1.3:1 d.r. for 35).[23ab] We attribute the stronger preference for the formation of $\mathbf{3 2}$ to the increased steric encumbrance of the Ni species relative to Pd, likely leading to the less sterically demanding mono-substituted olefin within substrate $\mathbf{3 1}$ being the favored coupling partner. Finally, to specifically probe how effective our conditions were at preventing alkene isomerization in an especially challenging case, we tested allyl-containing substrate $\mathbf{3 6}$. When using our standard conditions at $100{ }^{\circ} \mathrm{C}$, an excellent yield of spirocyclic product was observed, though the reaction proceeded with complete isomerization of the allyl group to give styrene 38 similar to what Skrydstrup reported[7] in related systems (cf. Scheme 1). Pleasingly, that ratio could be tuned simply by reducing the reaction temperature, with cyclization at $0{ }^{\circ} \mathrm{C}$ affording the non-isomerized alkene product 35 exclusively after $48 \mathrm{~h}$ of reaction time.

Similar to aryl triflates, vinyl triflates also performed extremely well, with substrates 39, 41, and 44 all affording the desired products in good to excellent yield (entries 8-10). In the case of product 40, it was formed in $90 \%$ yield, superior to the 
analogous Pd results, ${ }^{[23 c]}$ while in the more moderately yielding case of 42 , our conditions prevented alkene isomerization. This lack of isomerization is notable, as in the initial literature report using $\mathrm{Pd}$, a 1:1 mixture of $\mathbf{4 2}$ and two other alkene isomers (43) were obtained; only a full equivalent of added $\mathrm{Tl}\left(\mathrm{NO}_{3}\right)_{3}$ could suppress isomerization, thus highlighting how challenging this issue is for this substrate under Pd-based conditions.[23d]

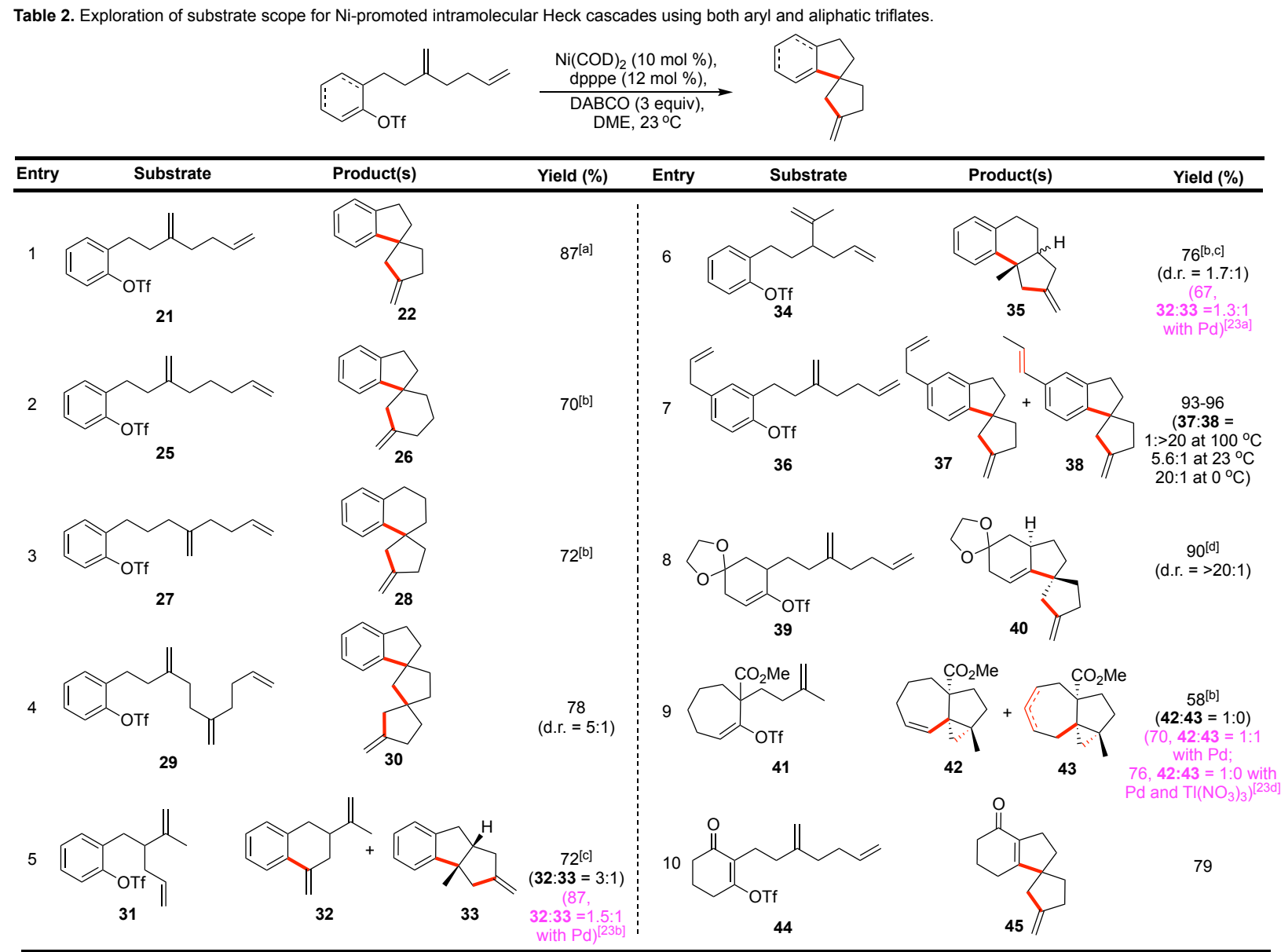

[a] Reaction performed on $10 \mathrm{mmol}$ scale. ${ }^{[\mathrm{b}]}$ Reaction performed at $80^{\circ} \mathrm{C}$. [c] Slightly improved regiocontrol and/or diastereocontrol versus analogous Pd-based Heck cyclization protocols. ${ }^{[d]}$ Reaction performed at $100^{\circ} \mathrm{C}$.

Next, having demonstrated the efficacy of our conditions for a variety of Heck cascades, we wondered how our Ni-based conditions would fare with some potentially more challenging substrates utilized in natural product synthesis. Specifically, we selected the Keay group's model system (i.e. 48, Scheme 2) ${ }^{[24]}$ from their synthesis of $(+)$ xestoquinone (5, cf. Scheme 1) and the Sarpong group's precursor aryl triflate $\mathbf{5 0}^{[4]}$ for a Larock annulation with $\mathbf{5 1}$ as part of their synthesis of pauciflorol F (6, cf. Scheme 1). For the first, our standard condition set afforded complex mixtures with significant formation of a dimeric by-product; however, when we ran a highly dilute reaction, the event proceeded smoothly. Additionally, we observed that performing the reaction under microwave conditions drastically decreased the time needed to reach completion to $2 \mathrm{~h}$ versus the $48 \mathrm{~h}$ required with traditional heating (similar in timescale to what the Keay group reported with $\mathrm{Pd}) .{ }^{[24]}$ When conducted in the presence of $(S, S)$-Chiraphos as ligand 
in DME, we observed the formation of tetracycle $\mathbf{4 9}$ in $82 \%$ yield and 39\% ee. We note that while we did screen several chiral bidentate phosphine ligands, we have not optimized this finding; forming this substrate enantioselectively is particularly challenging, even under Pd-based conditions, as evidenced by the Keay group's numerous studies on the subject.[25] For the Larock annulation leading to 52, our standard conditions were quite effective,[27] though adjustment of the ligand to DPEPhos provided superior results, with the desired indenone formed in 78\% yield and 2.9:1 regioselectivity; by contrast, the originally reported Pd- and Ni-variants by Sarpong ${ }^{[4]}$ and Kong, ${ }^{[17 b]}$ respectively, showed no regiocontrol. The efficacy of the latter reaction is significant based on Ni's previously reported reticence ${ }^{[8]}$ to react with sterically encumbered aryl sulfonates. Given that the Kong group observed no selectivity when using Ni and an aryl bromide coupling partner, we suspect the regioselectivity here arose from our use of the cationic pathway which is known to have a greater sensitivity to the electronic bias of electron-rich olefins. ${ }^{[1]}$

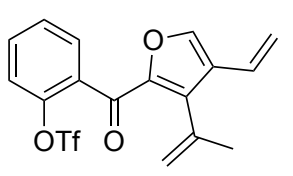

48
$\mathrm{Ni}(\mathrm{COD})_{2}(10 \mathrm{~mol} \%)$ $(S, S)$-chiraphos $(12 \mathrm{~mol} \%)$, DABCO (3 equiv),

DME $(0.05 \mathrm{M})$ $100^{\circ} \mathrm{C}, \mu \mathrm{W}, 0.5 \mathrm{~h}$ (82\%, 39\% ee)

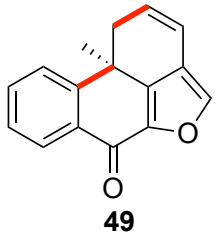

49

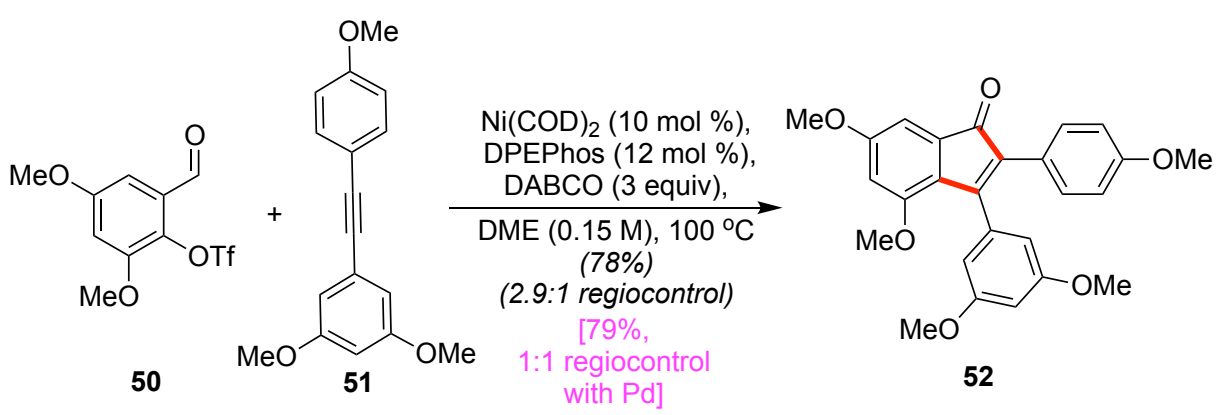

Scheme 2. Application of developed $\mathrm{Ni}$-Heck conditions to previous natural product total syntheses that utilized Pd-based Heck cascades.

Finally, given the success of the intermolecular variant leading to $\mathbf{5 2}$, we sought to probe additional cases of this type. In particular, we were intrigued by reports of an unusual intermolecular Heck cascade from the de Meijere and Zhou groups ${ }^{[26]}$ wherein following an initial Heck coupling, subsequent $\beta$-hydride elimination afforded significant amounts of alkene side-products as opposed to fully cyclized indenes from a second C-C bond formation. Since Ni undergoes $\beta$-hydride elimination less readily than Pd,[11a] we were curious to see if our conditions could lead to fully cyclized products instead. To our delight, as shown in Table 3, exposure of aryl triflate $\mathbf{5 3}$ to several different alkene coupling partners, or alkene $\mathbf{5 8}$ to different aryl triflates afforded not only fully cyclized materials, but also high selectivity for 6-endo cyclization as opposed to indene formation; in all cases, our standard conditions worked effectively when an excess of the alkene coupling partner was used (10 equiv), with some minor ligand screening leading to the optimized outcomes shown. While the novel regioselectivity was certainly the most striking feature of these reactions, we were also pleased to find that in nearly every case, no uncyclized sideproducts were observed (the exception was some minor adducts in the reaction involving 10). The predominance of the 6-endo-trig pathway is quite remarkable given the usual 
preference for 5-membered ring formation. ${ }^{[28]}$ While the exact rationale for this phenomenon is unconfirmed, we suspect the reversal in selectivity arose as a result of Ni's reported ${ }^{[29]}$ lack of preference for either 5-exo- or 6-endo-trig cyclization, thus the inherent $\beta$-selectivity[1] ${ }^{[1]}$ of the styrene moiety leads to the observed high 6-endo-trig selectivity. This hypothesis is supported by the observation that using the corresponding vinyl triflate (whose 1,4-diene would not have as strong a preference for $\beta$-selectivity) in place of the aryl triflate, only afforded products arising from 5-exo-trig pathways (results not shown). More globally, as the choice of ligand did impact the obtained selectivity, it is likely that dihydronaphthalene formation arose from the combination of metal, substrate, and ligand effects. Further studies to understand the genesis of this novel regioselectivity are ongoing and will be reported in due course. For now, some additional mechanistic studies are provided in the Supporting Information section, noting that the overall picture of the $\mathrm{Ni}$ Heck reaction is considerably less clear than its Pd-based counterpart.

Table 3. Preliminary exploration of intermolecular Nickel Heck cascades revealing some unique selectivity preferences over $\mathrm{Pd}$-based variants.
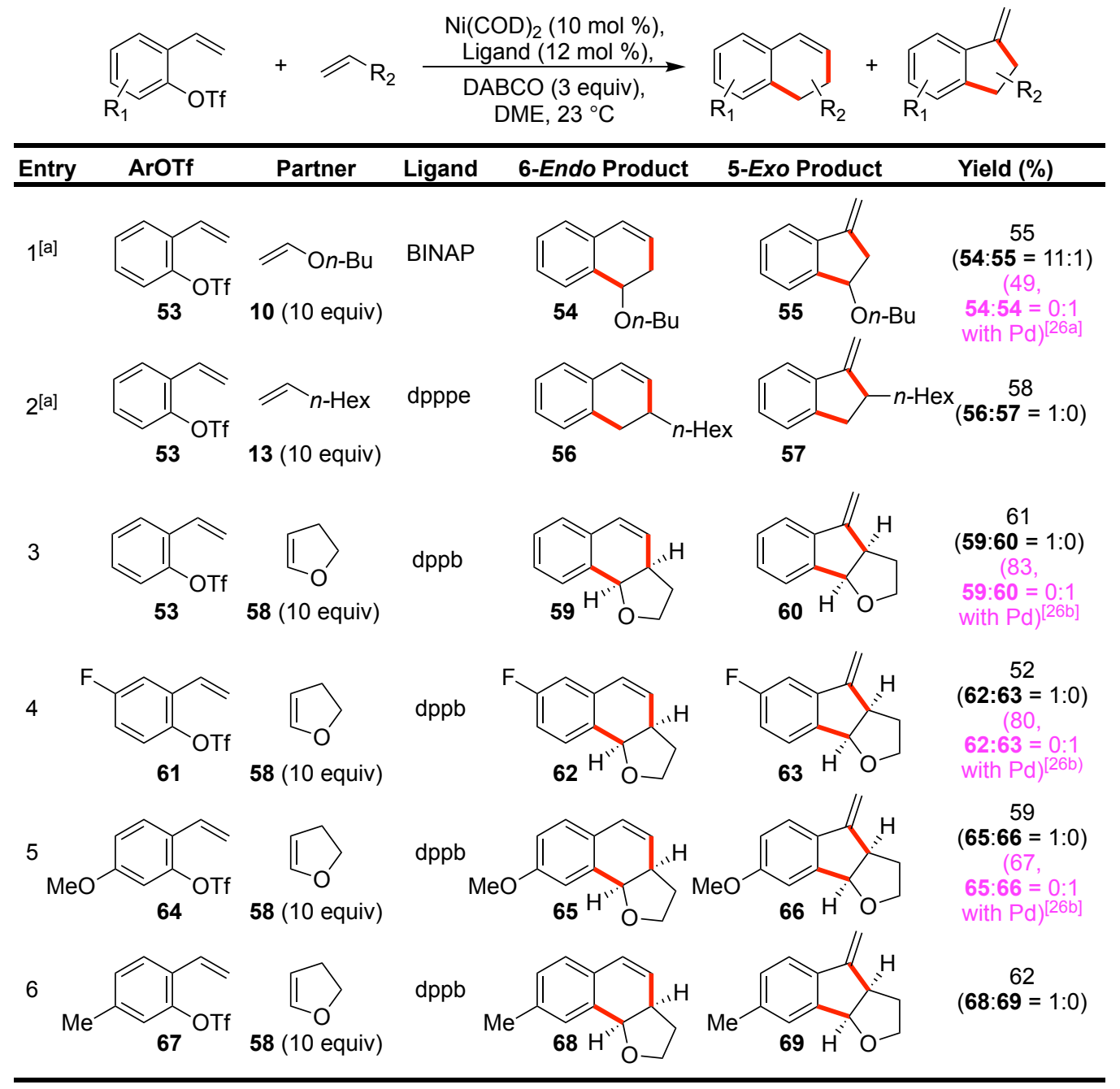

${ }^{[a]}$ Reaction performed at $60^{\circ} \mathrm{C}$. 
In conclusion, we have developed mild and highly efficient conditions to achieve base-mediated $\mathrm{Ni}$-Heck cascades leading to spirocycles and fused polycycles starting from aryl and vinyl triflates. These conditions provide a general approach which addresses the considerable challenge posed by $\mathrm{Ni}-\mathrm{H}$ isomerization observed in a myriad of previous studies. In addition, based on several direct comparisons to Pd-based variants, this reaction affords an effective and arguably more sustainable long-term alternative to $\mathrm{Pd}$ (given commensurate efficiency), with some cases highlighting improved and/or unique selectivity as a result of a switch in metal. Additional studies seeking to further expand on the discoveries reported here are currently underway.

Acknowledgments. We thank Dr. Antoni Jurkiewicz, Dr. Josh Kurutz, and Dr. C. Jin Qin for assistance with NMR and mass spectrometry, respectively. We also thank Prof. John S. Anderson (University of Chicago) for helpful conversations and Prof. Keary Engle (Scripps Research) for a sample of Ni(COD)(DQ). Financial support for this work came from the University of Chicago and the National Institutes of Health (R01-GM132570).

\section{References}

[1] For reviews, see: (a) I. P. Beletskaya, A. V. Cheprakov, Chem. Rev. 2000, 100, 30093066; (b) A. B. Dounay, L. E. Overman, Chem. Rev. 2003, 103, 2945-2963; (c) K. C. Nicolaou, P. G. Bulger, D. Sarlah, Angew. Chem. Int. Ed. 2005, 44, 4442-4489; (d) A. D. Meijere, T. Kurahashi, Compr. Organomet. Chem. III 2007, 11, 311-334; (e) M. Oestreich, The Mizoroki-Heck Reaction, John Wiley And Sons, 2009; (f) B. Ju, W. Kong, Asian J. Org. Chem. 2020, 9, 1154-1161; (g) D. Paul, S. Das, S. Saha, H. Sharma, R. K. Goswami, Eur. J. Org. Chem. 2021, 2057-2076.

[2] P. Hu, S. A. Snyder, J. Am. Chem. Soc. 2017, 139, 5007-5010.

[3] S. P. Maddaford, N. G. Andersen, W. A. Cristofoli, B. A. Keay, J. Am. Chem. Soc. 1996, 118, 10766-10773.

[4] J. L. Jeffrey, R. Sarpong, Org. Lett. 2009, 11, 5450-5453.

[5] (a) D. J. Kucera, S. J. O'Connor, L. E. Overman, J. Org. Chem. 1993, 58, 5304-5306; (b) M. E. Fox, C. Li, J. P. Marino, L. E. Overman, J. Am. Chem. Soc. 1999, 121, 5467-5480.

[6] (a) J.-N. Desrosiers, L. Hie, S. Biswas, O. V. Zatolochnaya, S. Rodriguez, H. Lee, N. Grinberg, N. Haddad, N. K. Yee, N. K. Garg, C. H. Senanayake, Angew. Chem. Int. Ed. 2016, 55, 11921-11924; (b) J.-N. Desrosiers, J. Wen, S. Tcyrulnikov, S. Biswas, B. Qu, L. Hie, D. Kurouski, L. Wu, N. Grinberg, N. Haddad, C. A. Busacca, N. K. Yee, J. J. Song, N. K. Garg, X. Zhang, M. C. Kozlowski, C. H. Senanayake, Org. Lett. 2017, 19, 33383341.

[7] T. M. Gøgsig, J. Kleimark, S. O. Nilsson Lill, S. Korsager, A. T. Lindhardt, P.-O. Norrby, T. Skrydstrup, J. Am. Chem. Soc. 2012, 134, 443-452.

[8] S. Z. Tasker, A. C. Gutierrez, T. F. Jamison, Angew. Chem. Int. Ed. 2014, 53, 18581861.

[9] For a review, see: (a) S. Bhakta, T. Ghosh, Adv. Synth. Catal. 2020, 362, 5257-5274. For additional leading references, see: (b) A. R. Ehle, Q. Zhou, M. P. Watson, Org. Lett. 2012, 14, 1202-1205; (c) M. R. Harris, M. O. Konev, E. R. Jarvo, J. Am. Chem. Soc. 2014, 136, 7825-7828 (d) X. Qin, M. W. Y. Lee, J. S. Zhou, Angew. Chem. Int. Ed. 2017, 56, 12723-12726; (e) J. M. Medina, J. Moreno, S. Racine, S. Du, N. K. Garg, Angew. 
Chem. Int. Ed. 2017, 56, 6567-6571; (f) M. R. Kwiatkowski, E. J. Alexanian, Angew. Chem. Int. Ed. 2018, 57, 16857-16860; (g) H. Long, K. Xu, S. Chen, J. Lin, D. Wu, B. Wu, X. Tian, L. Ackermann, Org. Lett. 2019, 21, 3053-3056; (h) Y.-L. Zheng, S. G. Newman, Angew. Chem. Int. Ed. 2019, 58, 18159-18164 (i) X. Huang, S. Teng, Y. R. Chi, W. Xu, M. Pu, Y. D. Wu, J. S. Zhou, Angew. Chem. Int. Ed. 2021, 60, 2828-2832; (j) J. S. Zhou, X. Huang, S. Teng, Y. R. Chi, Chem. Commun. 2021, 57, 3933-3936.

[10] Only one example using an alkene partner for two bond constructions as part of a Larock annulation has been reported to date to the best of our knowledge: (a) P. Shukla, C. H. Cheng, Org. Lett. 2006, 8, 2867-2869. For other examples using alkynes, see: (b) K.-C. Kong, C.-H. Cheng, J. Chem. Soc. Chem. Commun. 1991, 423424; (c) K. C. Kong, C. H. Cheng, Organometallics 2002, 11, 1972-1975; (d) D. K. Rayabarapu, C.-H. Cheng, Chem. Commun. 2002, 942-943.

[11] (a) B.-L. Lin, L. Liu, Y. Fu, S.-W. Luo, Q. Chen, Q.-X. Guo, Organometallics 2004, 23, 2114; (b) S. Z. Tasker, E. A. Standley, T. F. Jamison, Nature 2014, 509, 299-309; (c) V. P. Ananikov, ACS Catal. 2015, 5, 1964-1971.

[12] S. Iyer, C. Ramesh, A. Ramani, Tetrahedron Lett. 1997, 38, 8533-8536.

[13] J. S. Zhou, X. Huang, S. Teng, Y. R. Chi, Chem. Commun. 2021, 57, 3933-3936.

[14] Z. X. Wang, Z. Y. Chai, Eur. J. Inorg. Chem. 2007, 4492-4499.

[15] As one reflection of that rarity, the first report using triflates or mesylates under reducing conditions issued only recently: X. Huang, S. Teng, Y. R. Chi, W. Xu, M. Pu, Y. D. Wu, J. S. Zhou, Angew. Chem. Int. Ed. 2021, 60, 2828-2832.

[16] R. H. Morris, J. Am. Chem. Soc. 2014, 136, 1948-1959.

[17] (a) T. Ma, Y. Chen, Y. Li, Y. Ping, W. Kong, ACS Catal. 2019, 9, 9127-9133; (b) Y. Chen, Z. Ding, Y. Wang, W. Liu, W. Kong, Angew. Chem. Int. Ed. 2021, 60, 5273-5278; (c) F. Liu, Y. Li, X. Wang, Q. Qiang, Z. Yan, Y. Zhang, Z.-Q. Rong, Org. Chem. Front. 2021, 8, 3847-3852.

[18] For recent work with such partners as part of our own total synthesis endeavors, see Ref. 2 and (a) P. Hu, H. M. Chi, K. C. DeBacker, X. Gong, J. H. Keim, I. T. Hsu, S. A. Snyder, Nature 2019, 569, 703-707; (b) H. Yi, P. Hu, S. A. Snyder, Angew. Chem. Int. Ed. 2020, 59, 2674-2678; (c) H. M. Chi, C. J. F. Cole, P. Hu, C. A. Taylor, S. A. Snyder, Chem. Sci. 2020, 11, 10939-10944.

[19] (a) I. M. Kolthoff, M. K. Chantooni, S. Bhowmik, J. Am. Chem. Soc. 1968, 90, 23-28; (b) R. L. Benoit, D. Lefebvre, M. Fréchette, Can. J. Chem. 1987, 65, 996-1001.

[20] P. Dierkes, P. W. N. M. van Leeuwen, J. Chem. Soc. Dalton Trans. 1999, 1519-1530.

[21] L. Nattmann, R. Saeb, N. Nöthling, J. Cornella, Nat. Catal. 2020, 3, 6-13.

[22] V. T. Tran, Z. Q. Li, O. Apolinar, J. Derosa, M. V. Joannou, S. R. Wisniewski, M. D. Eastgate, K. M. Engle, Angew. Chem. Int. Ed. 2020, 59, 7409-7413.

[23] (a) M. M. Abelman, L. E. Overman, J. Am. Chem. Soc. 1988, 110, 2328-2329; (b) A. Ali, G. B. Gill, G. Pattenden, G. A. Roan, T. S. Kam, J. Chem. Soc. Perkin Trans. 1 1996, 1081-1093; (c) L. E. Overman, M. M. Abelman, D. J. Kucera, V. D. Tran, D. J. Ricca, Pure Appl. Chem. 1992, 64, 1813-1819; (d) R. Grigg, U. Sakee, V. Sridharan, S. Sukirthalingam, R. Thangavelauthum, Tetrahedron 2006, 62, 9523-9532.

[24] D. Lucciola, B. Keay, Synlett 2011, 2011, 1618-1622.

[25] (a) S. Y. W. Lau, B. A. Keay, Synlett 1999, 605-607; (b) S. Y. W. Lau, N. G. Andersen, B. A. Keay, Org. Lett. 2001, 3, 181-184; (c) D. Balcells, F. Maseras, B. A. Keay, T. Ziegler, Organometallics 2004, 23, 2784-2796; (d) D. A. Rankic, D. Lucciola, B. A. Keay, 
Tetrahedron Lett. 2010, 51, 5724-5727.

[26] (a) S. Bräse, J. Rümper, K. Voigt, S. Albecq, G. Thurau, R. Villard, B. Waegell, A. de Meijere, Eur. J. Org. Chem. 1998, 671-678; (b) J. Hu, H. Hirao, Y. Li, J. S. Zhou, Angew. Chem. Int. Ed. 2013, 52, 8676-8680.

[27] A related Ni catalyzed Larock annulation under base-mediated conditions was recently reported by the Rong group (see ref. 17c).

[28] The 5-exo-trig cyclization mode is well known to be prefered over the 6-endo-trig pathway in the Pd-Heck reportedly due to geometric constraints of the endo transition state (see ref. 1a) though examples of 6-endo-trig selectivity have been reported: see ref. 24-25 and (a) J. W. Dankwardt, L. A. Flippin, J. Org. Chem. 1995, 60, 2312-2313; (b) S. Lemaire-Audoire, M. Savignac, C. Dupuis, J. P. Genêt, Tetrahedron Lett. 1996, 37, 2003-2006; (c) H.-J. Ha, Y.-G. Ahn, J.-S. Woo, Bull. Korean Chem. Soc 1998, 19, 818-819. In some cases the observed 6-endo-trig selectivity instead arises from an initial 5-exo-trig cyclization followed by a cyclopropantation/ring opening sequence (d) Z. Owczarczyk, F. Lamaty, E. J. Vawter, E. Negishi, J. Am. Chem. Soc. 1992, 114, 10091-10092; (e) A. C. Albéniz, P. Espinet, Y. S. Lin, J. Am. Chem. Soc. 1996, 118, 7145-7152.

[29] B. Fiser, J. M. Cuerva, E. Gómez-Bengoa, Organometallics 2018, 37, 390-395. 